\title{
Backstage pass
}

\author{
Claudio Lamartina $^{1} \cdot$ R. Cecchinato ${ }^{1} \cdot{\text { M. } \text { Ismael }^{1} \cdot \text { C. Martini }^{1} \cdot \text { P. Berjano }}^{1}$
}

Published online: 19 July 2016

(C) Springer-Verlag Berlin Heidelberg 2016

On June 11th, the Editorial Board Meeting of European Spine Journal was held in Antwerp, Belgium. It was an interesting moment to analyze the past year and to plan the future of the Journal. The Editor provided us a summary of the activities of the Journal in 2015. Based on this, a thorough review of the different aspects involved was taken and critical points were discussed. As our Journal is the readers' Journal, we think it is fitting to offer you a quick overlook on what happens behind the scene. It is difficult to portray all the daily efforts involved in the editorial process (authors, reviewers, and editors) necessary to continually improve the quality of European Spine Journal, and to understand the complex mechanisms lying behind each printed copy of ESJ. We would, however, like to share the process of article selection with our readership.

In 2015, European Spine Journal received 1824 first submissions, 364 more submissions than the previous year. Of these 513 were published, which corresponds to a $28.1 \%$ acceptance rate (Fig. 1). These papers came from all over the world, showing the global profile of our Journal (Fig. 2). Moreover, 868 revised papers were re-submitted to ESJ. From these numbers alone you can imagine the quantity of work that lies behind each issue. And yet, that is not all. When a paper is submitted to the Editorial Manager System, on average it takes only 2.1 days to be assigned to a specific Editor from the Editorial Office, 9.9 days for reviewers to be assigned, and 45.5 days for the first decision to be taken by the Editor. A total of 8693 reviewers have been invited in 2015 to analyze the manuscripts, and

Claudio Lamartina

c.lamartina@chirurgiavertebrale.net

1 GSpine4, IRCCS Istituto Ortopedico Galeazzi, Via Riccardo Galeazzi, 4, 20161 Milan, Italy

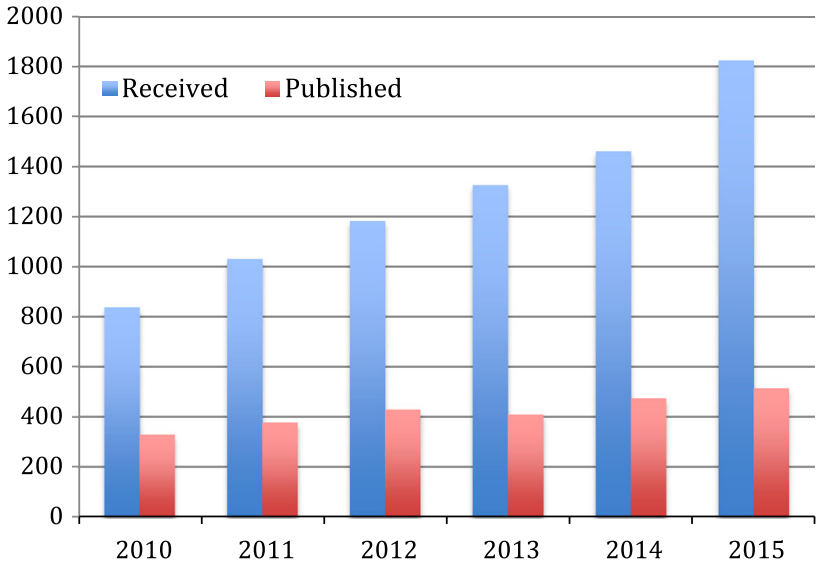

Fig. 1 Papers received and published from 2010 to 2015

\section{Origin of submitted papers}

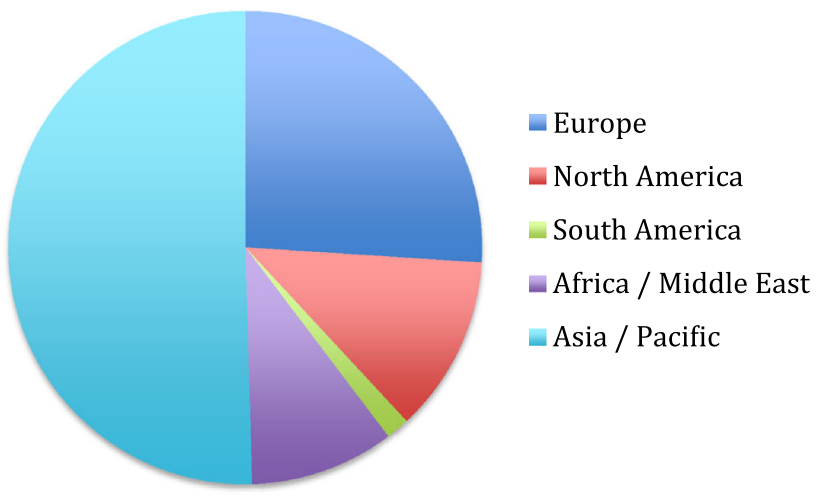

Fig. 2 Origin of submitted papers. $51.5 \%$ of Asia Pacific papers are submitted from China

their response was given in a mean of 21.5 days from the invitation date or 17 days from the date of review agreement. Each reviewer completes a mean of eight reviews per 
year, while maintaining a high standard. These numbers underline the efficacy of the review process.

Based on these and other data, we are developing a work plan to offer the best service to authors, reviewers and readers. Our final goal is to provide fast answers to authors, to realize a virtual real-time publication of your papers.

In spite of the increasing number of submissions, the Journal has to keep the number of published papers relatively stable. This means that the Editorial Board will pursue a strategy of selecting higher quality submissions. Our aim is to give the readers a high-quality global spine journal; unfortunately, this process requires a more rigid selection of papers.

In spite of this, we would like to invite authors not to be discouraged were they to receive a rejection letter; history is full of failures preceding big successes. Walt Disney was fired from a journal for 'lack of imagination and good ideas' before building his empire. Albert Einstein was considered "mentally slow" by his teacher. Abraham Lincoln lost eight elections before becoming President. The first time quantum mechanics was proposed to explain biological properties, specifically in explaining bird migration based as a reaction to the earth's magnetic field, the Editors of "Science" answered Klaus Schulten that a less "bold scientist" would have put this idea directly in the waste bin. We certainly will not be as blunt, so please feel free to send your best and innovative studies to European Spine Journal. We are looking forward to publishing your outstanding articles, to keep our Journal a cut above the rest.

\section{Compliance with ethical standards}

Conflict of interest The authors declare that they have no conflict of interest. 